DOI: $10.15593 / 2224-9354 / 2020.3 .5$

УДК 331.548:377

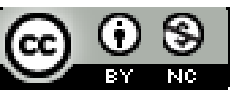

\title{
В.Н. Стегний
}

\section{СОЦИАЛЬНЫЕ ОРИЕНТАЦИИ УЧАЩИХСЯ НАЧАЛЬНОГО ПРОФЕССИОНАЛЬНОГО ОБРАЗОВАНИЯ}

На основе результатов конкретно-социологического исследования интерпретируются социальные ориентации молодежи начального профессионального образования. Сделан социологический анализ показателей жизненных ценностей, жизненного успеха, их ранжирования, уверенности в реализации своих жизненных планов; отмечена взаимосвязь у учащихся между их нравственными ценностями, знанием законов Конституции РФ, Трудового законодательства, Устава учебного заведения, его внутреннего распорядка и их поведением. Выделены ориентации учащихся на виды деятельности после завершения учебы в колледже: продолжение обучения в высшем или среднем специальном заведении; совмещение работы и учебы; работа в производственном коллективе.

Характеризуется понимание места и роли образования в жизни человека современного общества, мотивация ориентации на высшее образование, отношение респондентов к требованиям образования в информационно-инновационном обществе, его содержанию, состоянию, формам, получению его на протяжении всего периода производственной деятельности; ориентация на получение дополнительного образования по второй профессии, ранжированный ряд этих мотивов; факторы, препятствующие получению дополнительного образования; мотивация ориентации на получение высшего образования, особенности и структура этих мотивов. Показано отношение к цифровизации образования, новым информационным технологиям обучения, сочетание их с традиционными формами.

Определена ориентация респондентов на трудовую деятельность после завершения учебы в колледже, на формы собственности, виды трудовой деятельности, условия труда, а также особенности структуры мотивов выбора будущей трудовой деятельности.

Выявлены ориентации респондентов и их мотивы на совмещение учебы и работы после колледжа. Рассмотрены представления учащихся о компетенциях, которые необходимы работнику трудового коллектива для успешной адаптации на рынке труда, их ранжированный ряд.

Ключевые слова: учащаяся молодежь колледжа, социальные адаптации, жизненный успех, ценности, начальное профессиональное образование.

Объектом нашего исследования является молодежь XXI в., те, кто родились и выросли в России после 2000 г. ${ }^{1}$ Предмет исследования - их социальные ориентации, изучением которых занимаются почти все отрасли социального научного знания: социальная психология, философия, педагогика, культурология, политология. Среди них конкретное место занимает социология,

\section{(c) Стегний В.Н., 2020}

Стегний Василий Николаевич - д-р социол. наук, профессор кафедры социологии и политологии ФГБОУ ВО «Пермский национальный исследовательский политехнический университет», e-mail: socio@pstu.ru.

${ }^{1}$ Конкретно-социологическое исследование проводилось автором в 2019 г. в Лысьвенском политехническом колледже, среди обучающихся на начальном профессиональном образовании. Исследованием было охвачено 157 чел., среди которых в возрасте 16-17 лет - 80 \%, 18-19 лет $18 \%$ и 19 лет $-2 \%$. 
которая через свои категории, методы, теории интерпретирует данную проблему [1, с. 10-14].

Исследуя данную социальную группу и ее ценности, следует иметь в виду, что она является объектом и субъектом нового социального пространства и социального времени, нового типа общества - информационно-инновационного, у которого свой технологический уклад, основанный на кибер, цифре и информации. Здесь у личности иная роль, статус и механизм, как социализации, так и индивидуализации [2, с. 8-112, 168-279]. Это молодежь другой культуры [3, с. 117-444] и других ценностей [4, с. 92-177], у нее совершенно иная информационная культура [5, с. 11-50]. В этом обществе свои особенности имеет система образования [6, 37-39], качество которой рассматривается как основа повышения качества жизни [7, с. 95-96].

Существенной особенностью современного общества XXI в. является то, что оно стало обществом риска [8, с. 174-286], где социальные риски являются одним из определяющих факторов социализации личности [9, с. 107-108], что оказывает существенное влияние на социальные ориентации особенно молодежи.

В современной социологической литературе пока нет работ, посвященных социальным ориентациям молодежи начального профессионального образования, но недостатка в социологических исследованиях социальных ориентаций личности нет.

В этой связи интересными являются исследования социальных ориентаций молодежи следующих федеральных округов: Сибирского [10, с. 97-98], Приволжского [11, с. 78-143], Уральского [12, с. 60-63]. Новое поколение в разных регионах нашей страны находится в поисках своих новых идеалов и смыслов жизни [13, с. 80-87].

Характеризуя место социальных ориентаций у личности, следует особо отметить, что они являются ядром ее сознания, мировоззрения, культуры, жизненных планов, жизненной стратегии, жизненного пути, идеала, жизненного успеха и т.д. Они отражают ориентацию личности, как на социальное, так и индивидуальное будущее. Через них решается противоречие личности между идеалом и реальной действительностью. В них закладываются наиболее важные замыслы в жизни человека.

Среди опрошенных респондентов наиболее важными сегодня для себя считают:

каждый третий - самореализацию своего «я», своих способностей, интересов; удовлетворенность в жилье, питании, одежде, отдыхе;

каждый четвертый - социальную защищенность, безопасность, общение, наличие друзей, деятельность в коллективе;

каждый двадцатый - признание коллективом, уважение окружающих. 
Каждый второй среди опрошенных считает, что для достижения жизненного успеха необходимо умение сориентироваться в любой жизненной ситуации, находить выход из трудного положения.

Каждый третий выделяет: семейное счастье, любовь; честность, добропорядочность; материальный достаток; хорошее здоровье; наличие дела, бизнеса; стабильное положение в обществе, уверенность в завтрашнем дне.

Каждый четвертый отмечает: хорошие, воспитанные дети; наличие друзей; должностной рост, служебная карьера; высокая образованность, культура, наличие профессии, ремесла; осознание своей пользы обществу.

Каждый двадцатый подчеркивает: признание коллективности; уважение окружающих.

Зафиксированные социальные ориентации респондентов данной социальной группы, во-первых, не противоречат ценностям современного российского общества, его идеалам и устремлениям [14, с. 49-230]. Их ценностные ориентации коррелируются с подобными ориентациями учащейся молодежи [15, с. 49-137], они встраиваются в типологию ценностей, в основе построения которой лежит знание [16, с. 38], динамика их ориентаций вписывается в изменение данных ориентаций современной молодежи [17, с. 67-124].

Во-вторых, социальные ориентации молодежи данной группы имеют и свои особенности, что отличает их от подобных ориентаций учащихся, получающих среднее специальное образование [18, с. 136-140], студенческой молодежи [19, с. 73-96], россиян среднего возраста [20, с. 10-14], а также базовых ценностей россиян конца ХХ в. [21, с. 173-340].

Характеризуя ранжированный ряд ценностных ориентаций респондентов, следует особо отметить, что для них базовой, стержневой ориентацией является умение ориентироваться в любой жизненной ситуации, найти выход из трудного положения; самореализация своего «я», своих способностей, интересов. У других социальных групп современного общества эти ориентации прослеживаются значительно слабее. У них определяющей, как правило, является такая ценность, как семья, дети, любовь, дружба и т.д. Эта ценность и у наших респондентов оценивается высоко, но пока у них она не является определяющей.

Обращает на себя внимание и то, что такая ценность, как материальный достаток, не стоит в ранжированном ряду респондентов на первом месте и на последнем, а занимает то же место, что и другие ценности. Хотя эта ценность в других социальных группах нашего общества оценивается значительно выше. Учащаяся молодежь исходит, прежде всего, из того, что ей нужна профессиональная подготовка [22, с. 22-24], на основе которой можно решать материальные проблемы. Материальное благополучие преобладающее большинство респондентов рассматривает не как самоцель, а как средство своего жизненного пути.

Принципиальной особенностью социальных ориентаций респондентов является то, что они ориентируются не на одну какую-либо ценность, а на це- 
лую систему, которая будет меняться в их жизненном пути, она подвержена динамике.

Среди респондентов фиксируется достаточно высокий уровень уверенности в реализации своих жизненных планов в ближайшем будущем. Так, среди них 50 \% твердо уверены в их реализации, 30 \% выражают надежду, 15 \% испытывают беспокойство и тревогу, $2 \%$ - безысходность, 3 \% безразличны к этому.

Среди них основная группа не испытывает чувство страха за свое ближайшее будущее. Чувство страха постоянно и очень часто испытывают $5 \%$ респондентов, а у $95 \%$ в разных состояниях: $10 \%$ - незначительно, $50 \%$ время от времени, $35 \%$ - очень редко. У респондентов фиксируется достаточно твердая психическая устойчивость и уверенность в достижении успеха в своем ближайшем будущем.

В этой связи следует специально отметить роль нравственных ценностей в достижении успеха в жизни. Респондентам было предложено ответить на вопрос: «Можно ли достичь успеха в жизни, не нарушая правовых законов и нравственных норм?». Не смогли ответить на этот вопрос $20 \%$. Из тех, кто ответил, 10 \% считают, что достичь успеха, не нарушая законов и нравственных норм, нельзя, однако 70 \% считают, что достичь успеха в жизни, не нарушая правовых законов и норм морали, можно. Это показатель того, что у основной группы учащихся начального профессионального образования социальные ориентации опираются на нравственные ценности [23, с. 61-62], но есть среди них и такая группа, у которой нравственные ценности еще не стали основой жизненного успеха.

Очень слабо фиксируется у респондентов в их жизнедеятельности опора на правовые нормативные документы нашей страны. Так, среди них знакомы с Конституцией РФ, Трудовым законодательством в полной мере $1 / 10$, вообще не знакомы $1 / 10$, а 3/4 знакомы только частично. Такой же уровень фиксируется у них в знании Устава учебного заведения и правил его внутреннего распорядка. Отсутствие основных правовых знаний у учащихся начального профессионального обучения ничего хорошего не предвещает им в реализации жизненных планов и является показателем слабой гуманитарной подготовки данной системы образования. Конечно, это очень важный показатель образовательной неуспешности обучающихся, который вряд ли приведет их к социальной успешности [24, с. 36-41].

Чем намерены заниматься ученики после завершения учебы в системе начального профессионального образования? По этому показателю среди них выделились следующие типы: 1/3 собирается учиться; 1/5 - учиться и работать; 1/10 еще не определилась со своим выбором. Рассмотрим каждый из этих типов в отдельности. 
Первый тип - это те респонденты, которые ориентируются на продолжение образования в следующих формах: $50 \%$ - очно, $30 \%$ - заочно, 20 \% дистанционно, в таких видах как:

- профессиональные курсы - 1/3,

- среднее профессиональное образование - 1/10,

- высшее образование, бакалавриат, специалитет, магистратура - 1/2.

Данная группа респондентов определилась с местом и ролью образования в своем жизненном пути, исходя из требований к нему современного информационного, знаниевого общества. Гносеологической основой личности в этом обществе становится научность и образованность. Среди респондентов $90 \%$ считают, что знания и диплом, полученные в их учебном заведении, помогут им найти место в жизни, при желании открыть собственное дело, помогут в выборе места работы, могут быть гарантом при приеме на работу.

В современном информационно-инновационном обществе знания становятся основным показателем социального капитала личности [25, с. 46-47], но они вместе с информацией быстро стареют, и работник, чтобы адаптироваться к новым условиям, должен постоянно повышать свой образовательный и профессионально-квалификационный уровень. Среди респондентов 60 \% готовы к этому, 30 \% частично готовы и $10 \%$ еще не готовы.

Респонденты выбрали два пути повышения своего образовательного и квалификационно-профессионального уровня: а) дополнительное образование по второй профессии; б) получение более высокого уровня образования среднего специального или высшего.

Среди респондентов 20 \% уже в данном учебном заведении получают дополнительное образование по второй профессии. Среди них каждый пятый объясняет это тем, что хочет расширить свой кругозор, получить новые знания; беспокоится, что не сможет найти работу по основной специальности. Каждый десятый мотивирует тем, что в ходе обучения появился интерес к новой профессии; новые профессии более высоко оплачиваются; пользуются большим спросом на рынке труда; престижны в обществе.

Среди факторов, которые препятствуют получению дополнительного образования, респонденты называют следующие: 1/3 - отсутствие желания; 1/5 загруженность по основной учебе; 1/10 - пока не знают, куда применить дополнительные знания; 1/20 - возражают родителям.

Кроме получения дополнительного образования по второй профессии в колледже, основная масса респондентов в продолжении своего обучения ориентируются на получение высшего образования, ценность которого они видят в следующем: 1/5 - в том, что оно дает широкую перспективу в жизни, готовит к высококвалифицированной профессиональной деятельности, обеспечивает нормальные материальные условия жизни; 1/7 - в том, что оно дает возможность приносить наибольшую пользу обществу, готовит специалистов, 
способных работать в условиях инновационных технологий; 1/10 считает, что оно формирует научное мировоззрение; готовит специалистов, способных адаптироваться в кризисных условиях. Указанные учащимися начального профессионального образования мотивизационные компоненты являются важным фактором их будущей профессиональной успешности [26, с. 143-146].

Второй mun - это те респонденты, которые после завершения учебы в колледже ориентируются на трудовую деятельность. Среди них 40 \% собираются делать это в производственной сфере; $10 \%$ - в непроизводственной, $50 \%$ еще не определились со сферой трудовой деятельности. Что касается их выбора формы собственности, то они ориентируются на государственную, муниципальную - 25 \%; частную (ООО, НП) - 32 \%; хотят вести самостоятельную трудовую деятельность («самозанятость») $25 \%$; работать фрилансером $8 \%$; в акционерной $-8 \%$.

Указанные виды трудовой деятельности связаны и с предпринимательством, в содержание которого респонденты вкладывают следующее: одна из форм трудовой деятельности - 50 \%; большой труд, который не каждому по плечу, - 30 \%; общественно-полезная деятельность - $9 \%$.

Конечно, наши респонденты весьма далеки от понимания сущности, содержания предпринимательской деятельности. Это обусловлено их настоящим социальным статусом, социальной зрелостью, да и среди них около 70 \% не собираются этой деятельностью заниматься.

У респондентов весьма четко фиксируются ориентаџии на конкретные условия, характер труда. По значимости их можно разделить на три группы. Первая группа - наиболее значимые условия труда, их указал каждый третий среди респондентов. К ним относятся следующие: работа должна включать обязательно и интеллектуальные операции; работать 5 дней в неделю (8-часовой рабочий день); работать в помещении; выполнять индивидуальные задания; работать в группе; иметь личное рабочее место; работа должна иметь свободный режим; работать по требованиям работодателя.

Вторая группа респондентов, к ней относится каждый третий среди опрошенных, ориентируются на следующие условия труда: работать в соответствии с правилами внутреннего распорядка предприятия; работать 4 дня в неделю (10-часовой рабочий день); работать посменно; работать в одну смену; работа должна включать физические трудовые операции. Указанные условия труда респонденты считают менее важными, чем первой группы, но они все равно весьма значимые.

Третья группа, к ней относится каждый пятый респондент, они ориентируются на такие условия труда: возможность работать дистанционно; работа должна быть жестко привязана к рабочему месту; работа должна включать только интеллектуальные трудовые операции; работа вахтовым методом. Хотя ориентации на эти условия труда прослеживаются весьма слабо, но они есть 
и не учитывать их нет смысла. Главное в указанных респондентами условиях труда то, что они ориентируются на целую систему этих условий, это очень важно. Одни условия наиболее значимы, другие менее значимы, но все равно от них зависит отношение работника к своему коллективу, к своей работе.

Третий тип респондентов - это те, которые ориентируются на совмещение работы и учебы. Эта группа есть, хотя и небольшая, 10 \% среди них считают, что совмещение работы и учебы возможно, но 80 \% считают, что совмещать работу и учебу трудно, в чем они безусловно правы. Чем мотивируют они ориентацию на совмещение этих видов деятельности? Каждый второй среди опрошенных объясняет это желанием иметь свои личные деньги и материально не зависеть ни от кого. Каждый пятый мотивирует следующим: необходимо помогать родителям; обеспечить себя средствами существования; желанием усвоить полученную специальность на практике; расширить свое представление о специальности; получить производственный опыт; овладеть профессиональными навыками; сделать профессиональную карьеру; самореализоваться.

У этого типа респондентов в основе их ориентации лежит не один мотив, а целая система, что положительно характеризует их социальную зрелость.

Итак, исследуя социальные ориентации молодежи до 20 лет, начального профессионального образования, которая родилась и учится в XXI в., четко фиксируем, что она выстраивает свою профессиональную траекторию в процессе получения образования. Ее социальные ориентации отличаются от подобных ориентаций других групп молодежи XXI в., но они совпадают с подобными ориентациями современной личности, социальным будущим знаниевого, информационного общества. Зафиксированные социальные ориентации учащихся начального профессионального образования позволяют прогнозировать не только успешную профессиональную карьеру у большинства из них, но и социальную успешность. Конечно, их жизненный успех во многом будет зависеть от качества их образовательной и профессиональной подготовки. Поскольку его качество у групп разное, то и уровень, содержание социального успеха будет дифференцированным.

\section{Список литературы}

1. Стегний В.Н. Социологический подход к определению категорий «социальные установки и ценностные ориентации личности» // Вестник Пермского национального исследовательского политехнического университета. Социально-экономические науки. - 2017. - № 2. - С. 8-17.

2. Личность в информационно-инновационном обществе: моногр. / под ред. В.Н. Стегния. - Пермь: Изд-во Перм. нац. исслед. политехн. ун-та, 2015. $448 \mathrm{c.}$ 
3. Культура в информационно-инновационном обществе: моногр. / под общ. ред. В.Н. Стегния. - Пермь: Изд-во Перм. нац. исслед. политехн. ун-та, 2017. - 497 с.

4. Молодежь в информационно-инновационном обществе: моногр. / под ред. В.Н. Стегния. - Пермь: Изд-во Перм. нац. исслед. политехн. ун-та, 2019. 389 c.

5. Вишневский Ю.Р. Информационная культура уральского студенчества // Молодежь в информационно-инновационном обществе: моногр. / под ред. В.Н. Стегния. - Пермь: Изд-во Перм. нац. исслед. политехн. ун-та, 2019. - С. 11-31.

6. Малахова В.Г., Бокова Т.Н. Особенности образования в информационном обществе // Alma mater. Вестник высшей школы. - 2019. - № 11. - С. 36-40.

7. Стуканова И. Качество образования как индикатор и инструмент повышения качества жизни // Стандарты и качество. - 2020. - № 1(991). - С. 94-97.

8. Бек У. Общество риска на пути к другому модерну. - М.: Прогресстрадиция, 2000. -384 с.

9. Разов П.В., Штепа С.Е. Социальные риски как ключевой процесс социализации // Власть. - 2019. - № 11. - С. 106-109.

10. Немировский В.Г. Социально-политические ориентации сибирской молодежи // Социологические исследования. - 1996. - № 9. - С. 95-100.

11. Бокарев В.А. Трансформация изменений социально-политических ориентаций молодежи на рубеже XX-XXI вв. - М.: Крылья, 2008. - 184 с.

12. Банникова Л.Н., Боронина Л.Н., Вишневский Ю.Р. Новые явления в ценностных ориентациях уральского студенчества // Социологические исследования. - 2013. - № 2. - С. 58-67.

13. Овсянников А.А. Новое поколение: долгая дорога в поисках новых идеалов и смыслов жизни // Социологическая наука и социологическая практика. - 2015. - № 15. - С. 78-97.

14. О чем мечтают россияне: идеал и реальность / под ред. М.К. Горшкова, Р. Крумма, Н.Е. Тихонова. - М.: Весь мир, 2013. - 240 с.

15. Патрикеева Э.Т. Ценностные ориентации современной учащейся молодежи: моногр. - Арзамас, 2008. - 155 с.

16. Нархов Д.Ю., Нархова Е.Н. К проблеме культуры потребления информации в информационной безопасности молодежи // Молодежь в информационно-инновационном обществе: моногр. / под ред. В.Н. Стегния. - Пермь: Изд-во Перм. нац. исслед. политехн. ун-та, 2019. - С. 31-49.

17. Яковлева М.Н. Динамика ценностных ориентаций современной молодежи // Смысл жизни российской интеллигенции / под ред. Ж.Т. Тощенко; Рос. гос. технол. ун-т. - М., 2018. - 280 с.

18. Бюраева Ю.Г. Межнациональный аспект социальной мобильности выпускников ссуз // Вестник Пермского национального исследовательского политехнического университета. Социально-экономические науки. - 2018. № 4. - С. 135-143. 
19. Российское студенчество: идентичность, жизненные стратегии и гражданский потенциал: моногр. / под ред. В.А. Тишкова, В.В. Степанова; Ин-т этнологии и антропологии РАН. - М., 2014. - 342 с.

20. Маркова Ю.С. Социокультурные факторы становления и реализации ценностей россиян среднего возраста // Вестник Пермского национального исследовательского политехнического университета. Социально-экономические науки. - 2017. - № 4. - С. 200-209.

21. Базовые ценности россиян. Социальные установки. Жизненные стратегии. Мифы / под ред. А.В. Рябова, Е.Ш. Курбангалиевой. - М.: Дом интеллектуальной книги, 2003. - 448 с.

22. Вишневский Ю.Р., Шапко В.Т. Парадоксальный человек // Социологические исследования. - 2006. - № 6. - С. 21-26.

23. Беляева Е.В. Нравственные ценности эпохи постмодерна// Философия и социальные науки. - 2010. - № 1. - С. 60-64.

24. Зборовский Г.Е., Амбарова П.А. От образовательной неуспешности к социальной успешности // Высшее образование в России. - 2019. - № 11. C. 34-46.

25. Бурко В.А. О некоторых подходах к операционализации понятия «социальный капитал» // Современное общество: вопросы теории, методология, методы социальных исследований: материалы XVI (заочной) Всерос. науч. конф., посвящ. памяти проф. 3.И. Файнбурга. - Пермь, 2018. - С. 43-50.

26. Кустова Е.И. Мотивационные компоненты личности как фактор будущей профессиональной успешности // Вестник ЛГУ им. А.С. Пушкина. 2015. - № 1. - С. 140-148.

\section{References}

1. Stegnii V.N. Sotsiologicheskii podkhod k opredeleniiu kategorii "sotsial'nye ustanovki" i "tsennostnye orientatsii lichnosti" [Sociological approach to defining the categories of social attitudes and value orientations of a personality]. PNRPU Sociology and Economics Bulletin, 2017, no. 2, pp. 8-17.

2. Lichnost' $v$ informatsionno-innovatsionnom obshchestve [Personality in the information and innovative society]. Ed. V.N. Stegnii. Perm, Perm National Research Polytechnic University, 2015, 448 p.

3. Kul'tura $\mathrm{v}$ informatsionno-innovatsionnom obshchestve [Culture in the information and innovative society]. Ed. V.N. Stegnii. Perm, Perm National Research Polytechnic University, 2017, 497 p.

4. Molodezh' v informatsionno-innovatsionnom obshchestve [Young people in the information and innovative society]. Ed. V.N. Stegnii. Perm, Perm National Research Polytechnic University, 2019, 389 p. 
5. Vishnevskii Iu.R. Informatsionnaia kul'tura ural'skogo studenchestva [Information culture of the Ural students]. Perm, Perm National Research Polytechnic University, 2019, $389 \mathrm{p}$.

6. Malakhova V.G., Bokova T.N. Osobennosti obrazovaniia v informatsionnom obshchestve [Features of evaluation of education in information society]. Alma mater. Vestnik vysshei shkoly, 2019, no.11, pp. 36-40.

7. Stukanova I. Kachestvo obrazovaniia kak indikator i instrument povysheniia kachestva zhizni [The quality of education as an indicator and a tool for improving the quality of life]. Standarty $i$ kachestvo, 2020, no. 1(991), pp. 94-97.

8. Beck U. Die Risikogesellschaft: Auf dem Weg in eine andere Moderne (Russ. ed.: Bek U. Obshchestvo riska na puti k drugomu modernu. Moscow, Progress-traditsiia, 2000, 384 p.).

9. Razov P.V., Shtepa S.E. Sotsial'nye riski kak kliuchevoi protsess sotsializatsii [Social risks as a key aspect of the socialization process]. Vlast', 2019, no. 11, pp. 106-109.

10. Nemirovskii V.G. Sotsial'no-politicheskie orientatsii sibirskoi molodezhi [Socio-political orientations of the Siberian youth]. Sotsiologicheskie issledovaniia, 1996, no. 9, pp. 95-100.

11. Bokarev V.A. Transformatsiia izmenenii sotsial'no-politicheskikh orientatsii molodezhi na rubezhe XX-XXI vv. [Transformations of changes of socio-political orientations of young people at the turn of the 20th-21st centuries]. Moscow, Kryl'ia, 2008, 184 p.

12. Bannikova L.N., Boronina L.N., Vishnevskii Iu.R. Novye iavleniia v tsennostnykh orientatsiiakh ural'skogo studenchestva [New phenomena in value orientations of the Ural students]. Sotsiologicheskie issledovaniia, 2013, no. 2, pp. 58-67.

13. Ovsiannikov N.A. Novoe pokolenie: dolgaia doroga v poiskakh novykh idealov i smyslov zhizni [The new generation: Long road in search of new ideals and the meaning of life]. Sotsiologicheskaia nauka i sotsiologicheskaia praktika, 2015, no. 15 , pp. $78-97$.

14. Gorshkov M.K., Krumm R., Tikhonov N.E. O chem mechtaiut rossiiane: ideal i real'nost' [What the Russians are dreaming about: Ideal and reality]. Moscow, Ves' mir, 2013, $240 \mathrm{p}$.

15. Patrikeeva E.T. Tsennostnye orientatsii sovremennoi uchashcheisia molodezhi [Value orientations of the modern students]. Arzamas, Arzamas State Pedagogical Institute, 2008, $155 \mathrm{p}$.

16. Narkhov D.Iu., Narkhova E.N. K probleme kul'tury potrebleniia informatsii $\mathrm{v}$ informatsionnoi bezopasnosti molodezhi [On the problem of information consumption culture in the information security of the youth]. Molodezh' $v$ informatsionno-innovatsionnom obshchestve. Perm, Perm National Research Polytechnic University, 2019, pp. 31-49. 
17. Iakovleva M.N. Dinamika tsennostnykh orientatsii sovremennoi molodezhi [Dynamics of value orientations of modern youth]. Smysl zhizni rossiiskoi intelligentsii. Russian State University for the Humanities, Moscow, 2018, 280 p.

18. Biuraeva Iu.G. Mezhnatsional'nyi aspekt sotsial'noi mobil'nosti vypusknikov SSUZ [The inter-generational aspect of the social mobility of graduate students of secondary vocational educational institutions]. PNRPU Sociology and Economics Bulletin, 2018, no. 4, pp. 135-143.

19. Rossiiskoe studenchestvo: identichnost', zhiznennye strategii i grazhdanskii potentsial [Russian students: Identity, life strategies and civil potential]. Ed. V.A. Tishkov, V.V. Stepanov, Institute of Ethnology and Anthropology of RAS, Moscow, 2014, $342 \mathrm{p}$.

20. Markova Iu.S. Sotsiokul'turnye faktory stanovleniia i realizatsii tsennostei rossiian srednego vozrasta [Socio-cultural factors of values' formation and implementation among the middle-aged Russians]. PNRPU Sociology and Economics Bulletin, 2017, no. 4, pp. 200-209.

21. Bazovye tsennosti rossiian. Sotsial'nye ustanovki. Zhiznennye strategii. Mify [Basic values of the Russians. Social attitudes. Life strategies. Symbols. Myths]. Ed. A.V. Riabov, E.Sh. Kurbangalieva. Moscow, Dom intellektual'noi knigi, $448 \mathrm{p}$.

22. Vishnevskii Iu.R., Shapko V.T. Paradoksal'nyi chelovek [Paradoxical young man]. Sotsiologicheskie issledovaniia, 2006, no. 6, pp. 21-26.

23. Beliaeva E.V. Nravstvennye tsennosti epokhi postmoderna [Moral values of the postmodern era]. Filosofiia i sotsial'nye nauki, 2010, no, 1, pp. 60-64.

24. Zborovskii G.E., Ambarova P.A. Ot obrazovatel'noi neuspeshnosti k sotsial'noi uspeshnosti [From educational failure to social success]. Vysshee obrazovanie v Rossii, 2019, no. 11, pp. 34-46.

25. Burko V.A. O nekotorykh podkhodakh $\mathrm{k}$ operatsionalizatsii poniatiia "sotsial'nyi kapital" [Some approaches to the operationalization of the indicator "social capital" (methodological guidance on the development of the scale of social capital)]. Sovremennoe obshchestvo: voprosy teorii, metodologiia, metody sotsial'nykh issledovanii. Proceedings of XVI All-Russ. Sci.-Pract. Conf. in memory of Professor Z.I. Feinburg. Perm, November, 2018, pp. 43-50.

26. Kustova E.I. Motivatsionnye komponenty lichnosti kak faktor budushchei professional'noi uspeshnosti [Motivational components of the personality of students as a factor for future professional success]. Vestnik LGU im. A.S. Pushkina, 2015, no. 1 , pp. $140-148$.

Оригинальность $81 \%$

Получено 21.05.2020 Принято 19.06.2020 Опубликовано 28.09.2020 


\section{V.N. Stegniy}

\section{SOCIAL ORIENTATIONS OF STUDENTS OF PRIMARY VOCATIONAL EDUCATION}

The paper interpretes the social orientations of young people in primary vocational education, based on the results of a concrete sociological study. A sociological analysis has been made of indices of life values, success in life, their hierarchy, confidence in the realization of one's life plans. The author has observed a relationship between the students' moral values, knowledge of the provisions of the Constitution, Labour legislation, the Charter of the institution, its internal regulations and their behavior. The author highlights the orientation of students to activities following their university studies: continuing their academic progress at a higher or secondary specialized institution; combining work and study; working in a production team.

The author describes understanding of the place and role of education in human life in modern society, motivation of orientation towards higher education, the respondents' attitudes towards the requirements of education in the information-innovation society, its content, status, forms; acquisition of education during the whole period of labour activities; orientation to getting additional qualification in a second profession. The study ranks the number of those motives and discloses barriers to obtaining additional education, motivation of orientation towards higher education, characteristics and structure of these motives. Investigated also are an attitude to digitalization of education, new information technologies of training, their combination with traditional forms.

The papers also focuses on respondents' orientation to work after completing their college studies; to forms of ownership, types of work, working conditions; features of the structure of motives for choosing future work.

Finally, the author looks at orientations and their motives for combining study and work after college; students' ideas about the competencies that are necessary for the employee to successfully adapt to the labor market, offering their ranked series. education.

Keywords: college students, social adaptations, life success, values, primary professional

Vasiliy N. Stegniy - Doctor of Sociology, Professor, Department of Sociology and Political Science, Perm National Research Polytechnic University, e-mail: socio@pstu.ru.

Received 21.05.2020 Accepted 19.06.2020 Published 28.09.2020 